\title{
ASSESSING THE IMPACT OF BURNOUT SYNDROME ON ROMANTIC RELATIONSHIP SATISFACTION: THE DARK SIDE OF WORKPLACE BULLYING
}

Parisa Gharibi Khoshkar, Panteha Farmanesh, Gabriel Nweke

\section{Abstract}

The present study addressed the issue of whether occupational Burnout Syndrome (BS) is associated with Romantic Relationship Dissatisfaction (RRS) among academics; it was also expected that Workplace Bullying (WPB) moderates the relationship between these variables. A cross-sectional study was conducted by delivering the questionnaire surveys to the recruited sample group of 320 university lecturers from three different universities in Northern Cyprus to test the research hypothesis. Moderated multiple regression analysis was used to analyze the data. As it was hypothesized, our results indicated a negative association between burnout syndrome and romantic relationship satisfaction; indicating higher levels of burnout might lead to lower romantic relationship satisfaction. However, the proportion of romantic relationship satisfaction total score varied slightly when workplace bullying moderated this relationship. Our findings contribute to different scientific aspects by its valuable implications for researchers, practitioners, academicians, managers, and various organization staffs' self-awareness.

Keywords: romantic relationship satisfaction, burnout syndrome, organizational psychology, human resource management, workplace bullying, organizational behavior

JEL classification: L29; D91

\section{INTRODUCTION}

The importance of satisfaction in career and romantic relationships has received considerable attention during the past few decades. An increasing number of books and scholarly articles promoted the importance of maintaining the balance between these two dimensions since the work-family intervention has resulted in relationship dissolutions in recent decades (Tejada-Vera and Sutton 2010). Experiencing and elevating intimacy through romantic relationships plays a vital role in one's life fulfillment, which leads to physical and psychological well-being of both partners (Birditt and Antonucci 2007). However, it has been stated that partners with lower levels of psychological well-being report experiencing negative emotional states such as dissatisfaction, disappointment, and frustration in their romantic relationships while
Parisa Gharibi Khoshkar, PhD Candidate (corresponding author)

Assistant Lecturer

Faculty of Humanities

Girne American University

E-mail: parisakhoshkar@gau.edu.tr

Address: Via Mersin 10, Northern Cyprus, Turkey

Panteha Farmanesh, $\mathrm{PhD}$

Associate Professor Dr.

Faculty of Business and Economics

Girne American University

E-mail: pantehafarmanesh@gau.edu.tr

Gabriel Nweke, $\mathrm{PhD}$

Assistant Professor Dr.

Faculty of Humanities

Girne American University

E-mail: nwekegabriel@gau.edu.tr 
other individuals in quality relationships experience feelings of self-worth, happiness, and satisfaction (Lanz and Tagliabue 2007). Consequently, a growing body of universal research has indicated a significant increase in the number of broken-down marital and non-marital relationships across the world each year (Tejada-Vera and Sutton 2010; Zineldin and Vasicheva 2016), which could be the outcome of various predictors, such as lack of support (Cramer 2004), personality characteristics (Leonard and Roberts 1998), relationship conflict management (Gottman, 2014), stress (Green and Mitchell 2002; Bodenmann and Cina 2006), etc.

In terms of work dimension, to modern humans, working not only has some positive economic rewards but also it's a tool to reach goals and achievements beyond them, including self-esteem, motivation, selfperception, and identity formation (Repetti and Wang 2017). Apart from its many positive aspects, working could negatively affect different aspects of our lives, including physical, psychological, and interpersonal.

Occupational stress could be counted as one of the major causes of this harm, whereby individuals experience intense stress and health complaints through their jobs (Marchand et al. 2015). One of the many outcomes of work-related stress is burnout syndrome (BS), which affects employees' physical, emotional, and psychosocial state by undergoing emotional exhaustion (EE), depersonalization (DP), and lack of personal accomplishments (PA) (Maslach and Jackson 1981). Research supported that burnout has been experienced by those who deal with high loads of stress at work within a long period of time. One of the additional stress-related outcomes of work could be workplace bullying, which is one of the social stressors that affects the overall wellbeing of individuals at work through both directly or indirectly "harassing, offending, socially excluding someone or negatively affecting someone's work tasks ... repeatedly and regularly (e.g., weekly) and over a period of time (e.g., about six months)" (Einarsen et al. 2003, p.15). Workplace bullying (WB) implies any deliberate or undeliberate actions, attitudes, or practices of one or some members of an organization towards other members (McKay et al. 2008). Different studies investigated the negative impact of bullying on well-being and accordingly, it has been found that while some victims experience difficulties, such as posttraumatic stress disorder symptoms, including stress, anxiety, or depression; others might experience increased tendency towards asking for sickness absences or intentions to leave their organization (Hansen et al. 2006).

Amongst different varieties of occupations, this study is interested in academic career in order to investigate the negative influences of burnout syndrome on academics' romantic relationship satisfaction since teaching is a stressful job (Sava 2002). Teachers fulfill an enormously important role in the education system by taking shares in responsibility by training knowledgeable student in order to prepare them for a successful future. Research found that emotions are a significant, substantial, and effective element of teaching career. As it has been argued by Pintrich (1991), "emotions are intimately involved in virtually every aspect of the teaching and learning process and, therefore, an understanding of the nature of emotions within the school context is essential" (p. 199). There is a wide amount of literature on the influence of modern stress, especially work-related stress, on teachers' different life aspects. However, a limited number of studies have focused on the relationship between work-related stress and teachers' romantic relationship satisfaction. The existing gap in the literature relating these variables enabled the present study to investigate the interrelationship among burnout and romantic relationship satisfaction by exploring the moderating effect of workplace bullying within this relationship. Although some studies found a certain level of satisfaction to be achieved through the academic career (e.g. Winefield et al. 2003), a great deal of study results verified that teaching is highly associated with burnout (Gates 2007; Maslach, Schaufeli, and Leiter 2001; Schaufeli and Buunk 2003), and workplace bullying (e.g. Charilaos et al. 2015). Thus, the present study aimed to assess the relationship between such work-related stressors on academics' romantic relationships since the complications of such harms should be taken into account consequently (Van Droogenbroeck and Spruyt 2015).

Accordingly, the present study aims to review the most related empirical background studies regarding the research variables in the theoretical background section which is followed by research hypothesis and research model. Research participants and procedure, applied measurement instruments, and methods have been presented in section three. The next section includes data analysis of the study which follows by the discussion of the results in section 5 . The implications of our findings have been presented in section 6 that follows study limitations which could be implemented for further research in the future.

\section{THEORETICAL BACKGROUND AND HYPOTHESIS DEVELOPMENT}

For an individual to achieve life satisfaction, it is necessary to go through development successfully. This implies achievements in different life aspects, 
such as being involved in an intimate relationship and also engaging in a satisfying career. The significance of employment and intimate relationships as influential factors in one's social, personal, and career development has been highlighted in so many different theorists such as Maslow's Hierarchy of Needs (1943) and Erikson's Psychosocial development theory (1994). However, neither career nor romantic relationships can be satisfying for everyone all the time.

Although there are so many various factors that have a negative association with satisfaction, this study focused on the role of occupational stress in romantic relationship dissatisfaction as well as the moderating role of workplace bullying on this relationship among academics. Stress reveals if one feels incompatible of dealing with real or unreal demands of society and others; consequently, the outcome will exhibit itself in the form of physical or psychological symptoms (Lazarus and Folcman 1984). As it was stated in the previous literature, a wide range of studies found that work-related conditions of teaching in academia would lead the academics to undergo through burnout as a result of various predictors, such as working long hours, work overload, depletion of emotional resources, increased job demands, ambiguous duties, poor support, workplace conflicts, and poor payments (Barkhuizen and Rothmann 2008; Kinman and Jones 2008). According to the stress-divorce-model, external stress not only impacts the individuals' physical and psychological well-being but also it might spillover into their relationship with the romantic partner and eventually, it might contribute to relationship breakdowns (Bodenmann 2007). Rupert et al. (2012) mentioned to spillover as the ways which employees' experiences at work would influence their personal life and other ways round. A study by Kinnunen et al. (2006) investigated employees' job spillover into different life domains, including happiness and satisfaction in their personal/ family relationships. Accordingly, experiencing spillovers at work would lead to unhappiness and dissatisfaction in employees' intimate relationships. Considering burnout and workplace bullying as stressors in one's life, the experienced occupational stress could spillover into the affected individual's romantic relationships; resulting in relationship conflicts, which might eventually lead to relationship dissatisfaction and breakdowns (Falconier et al. 2015).

\subsection{Burnout Syndrome}

Work has been a very important element in the evolution of human civilizations. The significance of employment reveals itself in two of Erik Erikson's eight stages of psychosocial development, including industry vs. inferiority and also generativity vs. stagnation (Munley 1975). Abraham Maslow also regarded to employment as a tool to achieve our needs for safety, which could contribute to secure our needs for better health, wealth, property, and other personal life conditions after our biological needs are fulfilled sequentially (Jonas 2016).

Although undertaking a fulfilling career could contribute to one's life satisfaction in many positive ways, different factors such as social changes have had negative influences on the work culture and work conditions across history. The capitalist civilization which was created by the industrial revolution has brought enormous social changes to all crucial areas of the modern bourgeois world, including society, culture, economy, career, and interpersonal relationships (Kozak 2011). Individuals' lifestyles have also changed based on the variety of dynamic changes offered by postmodernism which resulted in undergoing conflicts in different life domains (Buschman and Brosio 2006). The increase of such problems caused by worklife factors has been a matter of concern for lots of researchers for several decades in order to find a balance (work-life balance, WLB) between these life domains (Adams and Jex 1999). The growing research has verified that the occupational burden of some jobs with high turnovers of demanding or troubled clients, such as healthcare professionals and teachers (Borg and Riding 1991) puts their employees under the risk of burnout; a term which was first originated by Herbert Freudenberger in 1974 to define employees' reaction towards experiencing chronic emotional, ethical and interpersonal stressors at work environment for a long time, which comprises three core dimensions, including "emotional exhaustion (EE), depersonalization (DP), and reduced personal accomplishments (RPA)" (Guntupalli et al. 2014, p. 139). According to Maslach (2003, p.191), "burnout is more a function of the situation than of the person" which encompasses a wide variety of somatic and psychosomatic symptoms, thus, individuals experience symptoms such as stress disorders, severe fatigue, headaches, emotional exhaustion, depression, cynicism, low self-esteem, the loss of interest for their job, and premature retirement (Cooper and Travers 2012).

\subsection{Romantic Relationship Dissatisfaction}

Regarding intimacy, Maslow affirmed that for individuals to accomplish their self-actualization it is essential to fulfill safety need and then to satisfy their love and belonging needs after their biological needs 
are fulfilled sequentially. Fulfilling these needs result in experiencing personal satisfaction and motivation (Einstein, Addams, and Roosevelt 2016). Along with Maslow's theory, the $6^{\text {th }}$ stage of psychosocial development theory by Erikson which is concerned with the crises regarding intimacy versus isolation in early adulthood emphasizes the significant role of intimate relationships in one's development of unique characteristics and attitudes in relation to himself and to his relationships with others and also to his environment during the life span (Santrock 2002). Individuals mostly start experiencing intimacy during their transitions from adolescence period towards early adulthood stage, which as a result, develops their identity. Various research supported the positive effect of intimacy on the development of positive feelings and also stress tolerance (Prager1991).

The development of romantic relationships occurs when individuals start exploring intimacy towards adulthood (Montgomery 2005). Within a well-functioning relationship, this enables both partners to encounter a sense of belonging, closeness, emotional security, and support (Stephanou 2012). Moreover, different studies linked the lack of such intimate relationships to some negative health outcomes, such as "loneliness and emotional distress" in either or both parties (Reis and Franks 1994, p.185). However, going through unresolved relationship conflicts in a dysfunctional relationship has been assumed as an important predictor of relationship dissolution (Røsand et al. 2014). As it was mentioned, modern societies face a remarkable annual divorce or breakdown in marital and non-marital relationships. In this regard, numerous sociological and psychological research has found so many different predictors contributing to relationship dissolutions, including age, race, social class (Bumpass, Martin, and Sweet 1991), stress (Crouter et al. 1989), and both partners' personality characteristics (Leonard and Roberts 1998). However, evaluating relationship satisfaction is so subjective that different couples consider different criteria to evaluate their relationship quality based on so many different personal and interpersonal characteristics (Li and Fung 2011).

\subsection{Antecedent to Burnout and Romantic Relationship Dissatisfaction}

The past few decades were the most challenging decades in the job market since lots of developments have taken place and work culture has been shaped so differently from the way it used to be in the past. Consequently, work demands have placed lots of limits on employees' role performance in their personal lives so that they had to allocate lots of efforts in occupying themselves with maintaining some balance between both work demands and their family roles, which results in developing high levels of psychological stress.

Although some optimal amount of stress has been a fundamental component of human survival (Boyce and Ellis 2005), exposure to prolonged occupational stress has been counted as a substantial risk factor for the development of burnout syndrome (Pines and Maslach 1978), thus, its psychological and physical symptoms impact certain aspects of one's life. The three dimensions of burnout, as it was mentioned in previous literature, might impact individuals' professional or personal life domains. One of the implications of burnout is its impact on individuals' mental health, through which burnout individuals might lack sexual interest, miscommunication, and fall into apathy in their interpersonal relationships, including their friends or their romantic partners as a result of depression and anxiety arose from burnout (Frone, Russell, and Cooper 1992).

H1: Occupational burnout syndrome has a significant negative relationship with romantic relationship satisfaction.

\subsubsection{Emotional Exhaustion and Romantic Relationship Dissatisfaction}

Maslach, Schaufeli, and Leiter (2001) pointed to emotional exhaustion as one of the components of burnout, which leads to chronic physical and emotional depletion. Research has consistently shown that lower level of intimacy is associated with relationship dissatisfaction (Patrick et al. 2007). According to the work-family balance model (Frone 2003), unpleasant characteristics of work domain could influence one's family or interpersonal domain, which might result in undergoing problems and conflicts within an intimate relationship, therefore, the victim might go through relationship breakups and dissolutions (Grzywacz and Marks 2000).

H1.a: Emotional exhaustion has a significant negative relationship with romantic relationship satisfaction.

\subsubsection{Depersonalization and Romantic Relationship Dissatisfaction}

According to attachment theory by Bowlby (1969/1982), all romantic relationships comprise 
three functional innate behavioral systems, including attachment, caring for the loved one, and sexual relationship, which he considered each of them as necessary to our survival and reproduction. While fulfilling these needs reflect satisfactory achievements in one's romantic relationship; malfunctioning and lacking any of them might lead to romantic relationship dissatisfaction (Mikulincer 2006). Different studies suggested that undergoing high levels of emotional exhaustion at work will subsequently result in depersonalization; a coping mechanism that distances the burned-out individual physically and emotionally. Depersonalization is a form of vulnerability to farther "physical assault ... threatening behavior... and verbal aggression", which reveals itself while the staffs manifest negative attitudes towards their clients (Winstanley and Whittington 2002, p.305). Given this, during the process of depersonalization, the burnedout individuals lose their sense of care for others as a human and start treating them more as the objects. In regard to the lack of care and interest as an outcome of depersonalization and its impact on individuals' relationships, the current study has hypothesized the following hypothesis:

H1.b: Depersonalization has a significant negative relationship with romantic relationship satisfaction.

\subsubsection{Reduced Personal Accomplishments and Romantic Relationship Dissatisfaction}

Burnt-out individuals might undergo some state of dissatisfaction towards self and their career accomplishment; a sense of negative evaluation of who they are and how they perform at their workplace, which might consequently lead to diminished self-esteem
(López et al. 2005). Several studies linked higher levels of self-esteem with high job motivation (Pierce et al. 1989) and high job success and higher compatibility in interpersonal relationships (Redenbach 1991). Several studies (e.g., Luteijn 1994) found a positive correlation between self-esteem and marital relationship satisfaction. Thus, the current literature supports the below hypothesis:

H1.c: Reduced personal accomplishment has a significant negative relationship with romantic relationship satisfaction.

\subsection{Moderating Role of Workplace Bullying}

As it was stated, workplace bullying is a workplace stressor through which the victims have been repeatedly exposed to various forms of harassment at workplace for a period, and as a result, they go through a set of somatic and psychosomatic symptoms that influence their lives in different ways (Matthiesen and Einarsen 2010). Referring to previous literature, research has supported the negative impact of stress on relationship satisfaction. According to this, the current study examines the role of workplace bullying as a moderator in the relationship between burnout syndrome and romantic relationship satisfaction.

H2: Workplace bullying moderates the relationship between occupational burnout and romantic relationship satisfaction among academics.

\section{5 Conceptual Model}

The following model (Figure 1) has been designed according to the previous research and the existing literature:

Figure 1. Conceptual Model

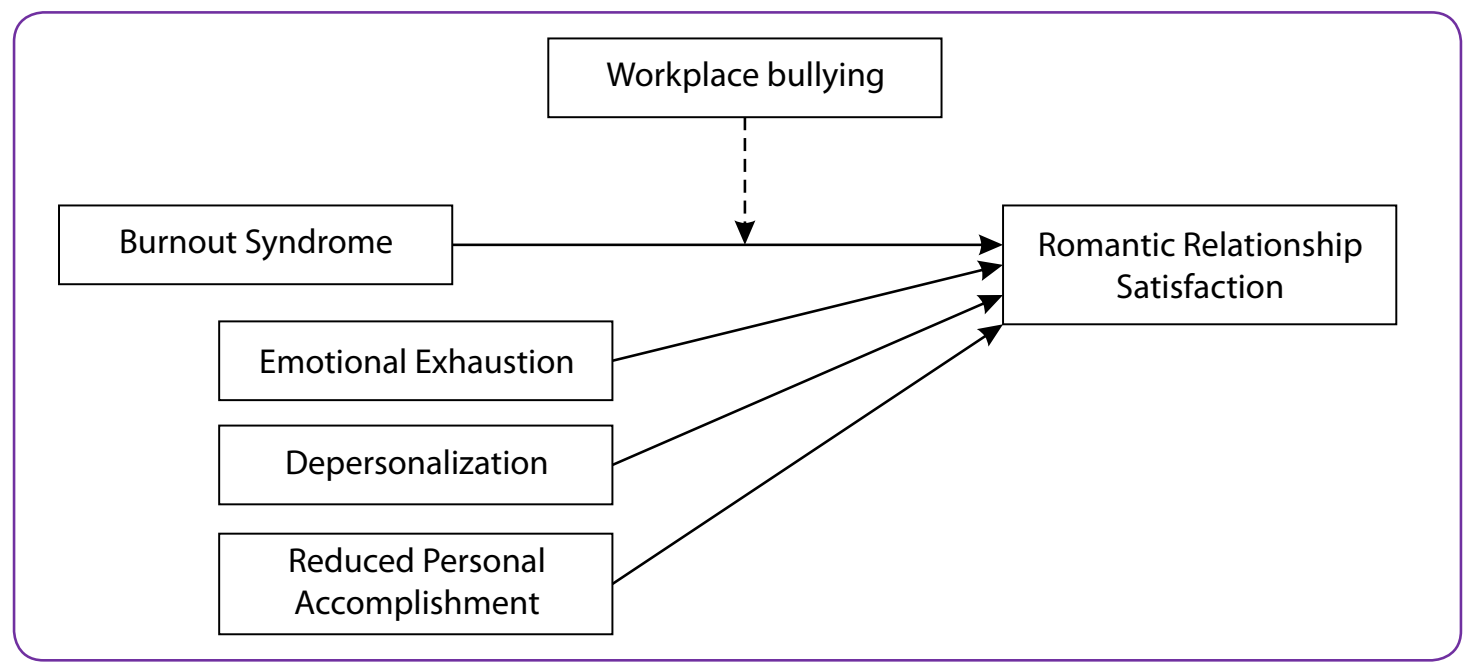




\section{METHODOLOGY}

\subsection{Participant and Procedure}

The current study aims to determine the relationship between occupational burnout syndrome and romantic relationship satisfaction among university lecturers with considering workplace bullying role as a moderating factor. Slovin's method was employed to calculate the minimum sample size necessary to achieve statistical power. Using convenience and purposive sampling, survey questionnaires were delivered to 365 university lecturers, from three different universities in Northern Cyprus to test the research hypothesis. Out of the 325 questionnaires collected, five were discarded due to incomplete responses. Accordingly, the final number of research participants was 320 . The fieldwork was carried out between July to August 2019, across three different universities in Kyrenia, Famugasta, and Nicosia in Northern Cyprus. Lecturers from different academic positions, gender groups, age groups, and cultural groups participated in this study.

\subsection{Measurement Instruments}

According to the existing literature and preceding studies, a questionnaire survey consisting of three different parts conducted to assess the relationship between occupational burnout and romantic relationship dissatisfaction and also to determine the effect of workplace bullying as a moderator affecting the strength of this relationship. The survey aimed to measure relevant variables, including burnout, workplace bullying, and romantic relationship satisfaction. Nine demographic questions were designed to measure the participants' personal data such as gender, nationality, positions, relationship- status, and so on.

Maslach Burnout Inventory-General self-report Scale (MBI) with high factorial validity_Embriaco et al. 2007; Rushton 2015), including 22 questions, was utilized to measure respondents' Burnout (Schutte et al. 2000). MBI is a 7- point Likert scale rates from Never (0) to Every day (6). The scale consists of 22 items including 3 different subscales such as emotional exhaustion (including 9 items), depersonalization (including 5 items), and personal accomplishments (including 2 items). The internal consistency of the scale was measured through Cronbach's a, indicating a reliability coefficient of 0.71 with the present sample, which was consistent with previous studies.

The Negative Act Questionnaire-Revised (NAQ-R) is a 23 items scale, which assessed respondents' perception of bullying at work environment (Einarsen, Hoel, and Notelaers 2009). A conducted pilot study also showed a high Cronbach's alpha of .86 with our current study sample. Respondents indicated their perceptions of workplace bullying on a scale from 1 (Never) to 5 (Daily).

Burns' Relationship Satisfaction Scale (RSAT; Burns and Sayers 1992) was applied to measure the different aspects of relationship satisfaction. The assessment's items measure respondents' level of satisfaction regarding their communication and openness, conflict resolution, intimacy and closeness, and so forth within their romantic relationships. The items were scored on a seven-point Likert scale, ranging from 0 (very dissatisfied) to 6 (very satisfied). The assessment's reliability has been examined and the result confirmed its high internal consistency with a high Cronbach's alpha of .92 .

\subsection{Methods}

The current study conducted a cross-sectional quantitative correlational design to determine the moderating role of workplace bullying on the relationship between occupational burnout syndrome and romantic relationship dissatisfaction among academicians from Girne American University GAU, Eastern Mediterranean University EMU, and Cyprus International University CIU. The data collected were cleaned and analyzed using SPSS 23.0 for Windows. Pearson correlation coefficient and moderated multiple regression analyses models were used to assess the linear relationship among all the variables, and the interactive role of occupational burnout syndrome/ workplace bullying on romantic relationship satisfaction respectively. As recommended by Kinman and Kenny (1986) the predictors variables were centered before creating the two-way interaction analysis. The level of significance was set to $p$ value of 0.05 .

\section{DATA ANALYSIS AND RESULTS}

\subsection{Descriptive Analysis}

The current study aimed to investigate the ways occupational burnout syndrome could relate to romantic relationship dissatisfaction and also verify whether workplace bullying has any moderating role in regard to this relationship among academicians. Participants' age ranged in three different groups, including less than $30(0 \%), 31-40(35 \%)$, and above $40(65 \%)$. In terms of gender classification, $60 \%$ of the sample was female and $40 \%$ were male. Of all participants, $31 \%$ of the sample group was local lecturers and $69 \%$ were foreigners. 
Table 1. Inter-correlation (Pearson's $r$ ) matrix of the study variables $(n=320)$

\begin{tabular}{|c|c|c|c|c|c|}
\hline Variables & WB & BS & RRS & $\mathrm{EE}$ & $\mathrm{D}$ \\
\hline Workplace bullying (WB) & - & & & & \\
\hline Burnout syndrome (BS) & $.428^{* *}$ & - & & & \\
\hline Romantic relationship satisfaction (RRS) & $-.554^{* *}$ & $-.942 * *$ & - & & \\
\hline Emotional exhaustion (EE) & $.412^{* *}$ & $.878^{* *}$ & $-.909 * *$ & - & \\
\hline Depersonalization (DP) & $.667^{* *}$ & $.538^{* *}$ & $-.703^{* *}$ & $.644^{* *}$ & - \\
\hline Reduced personal accomplishment & $-.167^{* *}$ & $.383^{* *}$ & $-.142^{*}$ & -.009 & $-.468^{* *}$ \\
\hline
\end{tabular}

Notes. ${ }^{* *}$ Correlation is significant at the 0.01 level (2-tailed)

* Correlation is significant at the 0.05 level (2-tailed)

Table 1 indicates the correlation analysis among the study variables of interest through Pearson's twotailed correlation analysis. Accordingly, the results showed a significant negative relationship between occupational burnout syndrome and romantic relationship satisfaction $r(318)=-.942, p<.0001$; suggesting that high levels of burnout syndrome might reduce individuals' romantic relationship satisfaction, which supported the first hypothesis of the current study $(\mathrm{H} 1)$. The results also demonstrated a negative significant relationship between emotional exhaustion and romantic relationship satisfaction $r(318)=$ $-.909, \mathrm{p}<.0001$, which was consistent with $\mathrm{H} 1$. a; predicting the likelihood of lower romantic relationship satisfaction in case of undergoing high emotional exhaustion. Accordingly, the results supported H1.b

Table 2. Testing the moderator effect of WB in the relationship between BS (predictor) and RRS (outcome) using moderated multiple regression

\begin{tabular}{clccccc}
\hline Model & & Sum of Squares & df & Mean Square & F & Sig. \\
\hline \multirow{2}{*}{1} & Regression & 35511.033 & 2 & 17755.517 & 1695.246 & \\
& Residual & 3320.167 & 317 & 10.474 & & \\
& Total & 38831.200 & 319 & & 1293.623 & $.000^{\mathrm{c}}$ \\
& Regression & 35907.434 & 3 & 11969.145 & & \\
& Residual & 2923.766 & 316 & & & \\
& Total & 38831.200 & 319 & & & \\
\hline
\end{tabular}

a. Dependent Variable: Romantic Relationship Satisfaction

b. Predictors: (Constant), Workplace Bullying, Burnout Syndrome

c. Predictors: (Constant), Workplace Bullying, Burnout Syndrome, workplace bullying and burnout syndrome

Table 3. Coefficients of WB, BS, and BS*WB

\begin{tabular}{|c|c|c|c|c|c|c|c|c|}
\hline & & \multicolumn{2}{|c|}{$\begin{array}{l}\text { Unstandardized } \\
\text { Coefficients }\end{array}$} & \multirow{2}{*}{$\begin{array}{c}\text { Standardized } \\
\text { Coefficients } \\
\text { Beta }\end{array}$} & \multirow[b]{2}{*}{$\mathrm{t}$} & \multirow[b]{2}{*}{ Sig. } & \multicolumn{2}{|c|}{$\begin{array}{c}\text { 95.0\% Confidence } \\
\text { Interval for B }\end{array}$} \\
\hline & & $B$ & Std. Error & & & & Lower Bound & Upper Bound \\
\hline \multirow[t]{3}{*}{1} & (Constant) & 3.545 & .181 & & .000 & & -.356 & .356 \\
\hline & Burnout Syndrome & -.665 & .014 & -.863 & -47.477 & 1.000 & -.692 & -.637 \\
\hline & Workplace Bullying & -.285 & .028 & -.184 & -10.141 & .000 & -.340 & -.230 \\
\hline \multirow[t]{4}{*}{2} & (Constant) & -.641 & .196 & & -3.269 & .000 & -1.028 & -.255 \\
\hline & Burnout Syndrome & -.669 & .013 & -.868 & -50.748 & .001 & -.695 & -.643 \\
\hline & Workplace Bullying & -.439 & .035 & -.284 & -12.406 & .000 & -.509 & -.370 \\
\hline & $\begin{array}{l}\text { Workplace bullying and } \\
\text { burnout syndrome }\end{array}$ & -.015 & .002 & -.144 & -6.545 & .000 & -.010 & -.019 \\
\hline
\end{tabular}

a. Dependent Variable: Romantic Relationship Satisfaction 
by demonstrating a negative significant relationship between depersonalization and romantic relationship satisfaction $r(318)=-.703, p<.0001$. Furthermore, the study results indicated a negative significance among reduced personal accomplishment and romantic relationship satisfaction $r(318)=-.142, p<.005$, which supports the proposed hypothesis regarding to the third component of burnout (H1.c).

\subsection{Moderation Test}

To test the hypothesis $(\mathrm{H} 2)$ which predicted workplace bullying moderating effect in the relationship between burnout syndrome and romantic relationship satisfaction, a moderated multiple regression analysis was conducted. The overall model was significant, $R^{2}=.925, F(3,316)=1293.6, p<.0001$, this implies the significant impact of workplace bullying as a moderator in the relationship among burnout and romantic relationship satisfaction.

During the first step of regression analysis, two variables were included, including burnout syndrome total scores and workplace bullying total score. These variables accounted for a significant amount of variance in total romantic relationship satisfaction scores, $R^{2}=.914, F(3,316)=1695.2, p<.0001$. In the second and final step of the analysis, an interaction term between burnout syndrome scores and workplace bullying scores was created, which is counted for a significant increase in the proportion of the variance in romantic relationship satisfaction total scores, $\Delta R^{2}=.01, \Delta F(1,316)=42.84, p<.001, \mathrm{~b}=0.14, t(316)=$ $6.54, p<.001$. The results of the analysis showed a $1 \%$ increase in the variation in romantic relationship satisfaction due to the current study's moderator through which the moderating effect of workplace bullying in the relationship between burnout syndrome and romantic relationship satisfaction was indicated. The $1 \%$ increase in the $R^{2}$ which indicated the moderating effect of workplace bullying in the relationship between burnout and romantic relationship satisfaction is supporting as follows in Table 4.

\section{DISCUSSION}

The present study was conducted among the sample population of university lecturers in Northern Cyprus by aiming to examine the likelihood of romantic relationship dissatisfaction by considering the role of occupational burnout syndrome and also the moderating effect of workplace bullying within the developed hypothesis. To test the research hypothesis, three instruments with very high-value psychometric properties were conducted to 320 university lecturers in Cyprus. The results of the present research are in confirmatory with the previous literature, stating that different factors such as excessive stress (Lazarus and Folcman 1984) would contribute to teachers' burnout, as the study results demonstrated high scores in burnout (e.g., Gates 2007; Van Droogenbroeck and Spruyt 2015). Consequently, our finding revealed the negative impact of occupational stress on romantic relationship satisfaction, as a likelihood of relationship satisfaction has been found through the data analysis. The degree of association found between burnout and the romantic relationship satisfaction was in line with our literature (e.g., Bodenmann 2007; Falconier et al. 2015; Frone et al. 1992), arguing that burnout has a negative impact on individuals in terms of their tendencies towards sexual relationships, communication, affection level, intimacy, and their perceived self- esteem. The results of our study demonstrated that individuals with higher scores in burnout reported lower scores in the above-mentioned elements regarding their romantic relationships, which indicates a rise in relationship conflicts level that being unable to manage these relationship problems might lead to relationship satisfaction and eventually the relationship might fail (Frone 2003; Røsand et al. 2014). Thus, it is noteworthy that the findings of the study supported all of our main hypothesis, proposing that that burnout and its components are negatively related to romantic relationship satisfaction; which was consistent with the stress-divorce model. Based on this theoretical model, the external stressors will eventually result in relationship dissolution by spilling over into the stress-affected individual's romantic relationship,

Table 4. Model Summary

\begin{tabular}{cccccccc}
\hline Model & $\mathrm{R}$ & R Square & $\begin{array}{c}\text { Adjusted R } \\
\text { Square }\end{array}$ & $\begin{array}{c}\text { Std. Error of the } \\
\text { Estimate }\end{array}$ & \multicolumn{2}{c}{$\begin{array}{c}\text { R Square } \\
\text { Change }\end{array}$} & Sig. F Change \\
\hline 1 & $.956^{\mathrm{a}}$ & .914 & .914 & 3.236 & .914 & .000 \\
2 & $.962^{\mathrm{b}}$ & .925 & .924 & 3.042 & .010 & .000 \\
\hline
\end{tabular}

a. Predictors: (Constant), Workplace Bullying, Burnout Syndrome

b. Predictors: (Constant), Workplace Bullying, Burnout Syndrome, workplace bullying and burnout syndrome 
however, the relationship between burnout syndrome and romantic relationship satisfaction has never been exclusively studied by the previous studies as a sole research area. Hence, the present study is unique in terms of its findings in this regard.

Furthermore, the above mentioned theoretical model was also in line with our last research hypothesis, indicating the moderating effect of workplace bullying as a predictor of the likelihood of romantic relationship dissatisfaction while the academicians underwent burnout at the workplace. According to data analysis, a significant increase was demonstrated in the proportion of the variance in the total scores of respondents' romantic relationship satisfaction after the workplace bullying and burnout interacted with one another. In this regard, our findings were supported the previous literature by Hansen et al., (2006), stating that bullying victims go through symptoms related to stress disorder, which might subsequently spread into their relationship and end up in breakups.

\section{IMPLICATIONS}

In line with previous research, the present study has contributed to filling an existing gap in the literature on burnout, romantic relationship, and workplace bullying studies by investigating the relationship between occupational burnout syndrome and romantic relationship satisfaction at the existence of moderating role of workplace bullying among university lecturers in Northern Cyprus. Being the first work to explore the relationship between burnout syndrome and romantic relationship satisfaction in Northern Cyprus, the present study offered a new insight into work-life studies. Accordingly, our main findings indicated a significant proportion of variance in romantic relationship satisfaction while the academics scored higher in burnout, along with the interaction of workplace bullying within this relationship. This implies the importance of awareness and management on occupational stress, including burnout and workplace bullying in order to enable individuals to save the other life domain of romantic relationships. Moreover, our findings have numerous implications for researchers, practitioners, academicians, managers, various organization staff. Our findings enable organizational developments by making efforts in boosting their workplaces through getting conscious over occupational stress, organizational misbehaviors, and the ways these elements impact their employees' intimate relationships, since their romantic relationship satisfaction could impact their functions at work positively (Bowen, Edwards, and Cattell 2018).
Moreover, by raising awareness over the relationship between the study variables, our findings benefit the affected individuals to seek therapeutic help regarding their burnout syndrome along with bullying experiences at work, to prevent failures in their romantic relationships.

\section{LIMITATIONS AND FURTHER RESEARCH}

The present study had some certain limitations, which can contribute to further future research relating to our research topic. First, the researchers were limited with the geographical location, thus, our findings represent only academicians in Northern Cyprus. Due to this, further research is strongly recommended to be conducted in other countries by considering the role of culture in this regard. In current study literature, spillover theory was applied as a one-directional approach to explaining the association between study variables, including occupational burnout and romantic relationship satisfaction. However, according to the reciprocal nature of such theories, future studies might consider a multi-dimensional approach of spillover in order to examine study variables in various levels and directions. During the present study, the dispositional attribution of individuals' personality type was ignored. Personality is an important predictor to all our variables of interest since a great deal of research found associations between personality and our study variables, including burnout (Alarcon, Eschleman, and Bowling 2009; Cano- García, Padilla- Muñoz, and Carrasco-Ortiz 2005), romantic relationship satisfaction (White, Hendrick, and Hendrick 2004), and workplace bullying (Mathisen, Einarsen, and Mykletun 2011). Therefore, we suggest future research to replicate the present study results in terms of the role of personality type. The situational attribution such as culture shock which might moderate the correlation between the study variable could be considered as a valuable moderator in this regard. Furthermore, the present study was not only limited by time but also the researchers were limited in any interference with the study variables due to its cross-sectional design within its given population; thus, future studies might consider conducting the relevant research topic with any experimental or longitudinal designs. 


\section{REFERENCES}

Adams, G. and Jex, S. 1999. Relationships Between Time Management, Control, Work-Family Conflict, and Strain. Journal of Occupational Health Psychology 4(1): 72-77.

Alarcon, G., Eschleman, K. J. and Bowling, N. A. 2009. Relationships between personality variables and burnout: A meta-analysis. Work and stress 23(3): 244-263.

Barkhuizen, N. and Rothmann, S. 2008. Occupational stress of academic staff in South African higher education institutions. South African journal of psychology 38(2): 321-336.

Baron, R. M. and Kenny, D. A. 1986. The moderator-mediator variable distinction in social psychological research: Conceptual, strategic, and statistical considerations. Journal of personality and social psychology 51(6): 1173.

Bodenmann, G. 2007. Dyadic coping and the 3-phase-method in working with couples. Innovations in clinical practice: Focus on group and family therapy: 235-252.

Bodenmann, G. and Cina, A. 2006. Stress and coping among stable-satisfied, stable-distressed and separated/divorced Swiss couples: A 5-year prospective longitudinal study. Journal of Divorce \& Remarriage 44(1-2): 71-89.

Borg, M. G. and Riding, R. J. 1991.Occupational stress and satisfaction in teaching. British Educational Research Journal 17: 263-281.

Bowen, P., Govender, R., Edwards, P. and Cattell, K. 2018. Work-related contact, work-family conflict, psychological distress and sleep problems experienced by construction professionals: an integrated explanatory model. Construction Management and Economics 36(3): 153-174.

Boyce, W. T. and Ellis, B. J. 2005. Biological sensitivity to context: I. An evolutionary-developmental theory of the origins and functions of stress reactivity. Development and psychopathology 17(2): 271-301.

Birditt, K. S. and Antonucci, T. C. 2007. Relationship quality profiles and well-being among married adults. Journal of Family Psychology 21(4): 595.

Buck, E. 2010. Relationship breakups: Are they all bad? (Doctoral dissertation, Texas Tech University).

Bumpass, L. L., Martin, T. C. and Sweet, J. A. 1991. The impact of family background and early marital factors on marital disruption. Journal of Family Issues 12: 22-42.

Burns, D. D. and Sayers, S. L. 1992. Development and validation of a brief relationship satisfaction scale. Unpublished manuscript.

Buschman, J. and Brosio, R. A. 2006. A critical primer on postmodernism: Lessons from educational scholarship for librarianship. The Journal of academic librarianship 32(4): 408-418.

Cano-García, F. J., Padilla-Muñoz, E. M. and Carrasco-Ortiz, M. Á. 2005. Personality and contextual variables in teacher burnout. Personality and Individual differences 38(4): 929-940.
Charilaos, K., Michael, G., Chryssa, B. T., Panagiota, D., George, C. P. and Christina, D. 2015. Validation of the Negative Acts Questionnaire (NAQ) in a sample of Greek teachers. Psychology 6(01): 63.

Cooper, C. and Travers, C. 2012. Teachers under pressure: Stress in the teaching profession. Routledge.

Cramer, D. 2004. Emotional support, conflict, depression, and relationship satisfaction in a romantic partner. The Journal of Psychology 138(6): 532-542.

Crouter, A. C., Perry-Jerkins, M., Huston, T. L. and Crawford, D. W. 1989. The influence of work-induced psychological states on behavior at home. Basic and Applied Social Psychology 10: 273-292.

Einarsen, S., Hoel, H., Zapf, D. and Cooper, C. 2003. The concept of bullying at work. In S. Einarsen, H. Hoel, D. Zapf, and C. Cooper (Eds.), Bullying and emotional abuse in the workplace: International perspectives in research and practice (pp. 3-31). London: Taylor and Francis.

Einarsen, S., Hoel, H. and Notelaers, G. 2009. Measuring exposure to bullying and harassment at work: Validity, factor structure and psychometric properties of the Negative Acts Questionnaire-Revised. Work and Stress 23(1): 24-44.

Einstein, A., Addams, J. and Roosevelt, E. 2016. Maslowss hierarchy of needs.

Embriaco, N., Papazian, L., Kentish-Barnes, N., Pochard, F. and Azoulay, E. 2007. Burnout syndrome among critical care healthcare workers. Current opinion in critical care 13(5): 482-488.

Erikson, E. H. 1994. Identity and the life cycle. WW Norton and Company.

Falconier, M. K., Nussbeck, F., Bodenmann, G., Schneider, H. and Bradbury, T. 2015. Stress from daily hassles in couples: Its effects on intradyadic stress, relationship satisfaction, and physical and psychological well-being. Journal of marital and family therapy 41(2): 221-235.

Frone, M. R., Russell, M. and Cooper, M. L. 1992. Antecedents and outcomes of work-family conflict: testing a model of the work-family interface. Journal of applied psychology 77(1): 65.

Frone, M. R. 2003. Work-family balance. Handbook of occupational health psychology 7: 143-162.

Gates, C. H. 2007. Factors related to burnout in North Carolina public school teachers.

Gottman, J. M. 2014. What predicts divorce?: The relationship between marital processes and marital outcomes. Psychology Press.

Green, R. J. and Mitchell, V. 2002. Gay and lesbian couples in therapy: Homophobia, relational ambiguity, and social support.

Grzywacz, J. G. and Marks, N. F. 2000. Reconceptualizing the work-family interface: An ecological perspective on the correlates of positive and negative spillover between 
work and family. Journal of occupational health psychology 5(1): 111.

Guntupalli, K. K., Wachtel, S., Mallampalli, A. and Surani, S. 2014. Burnout in the intensive care unit professionals. Indian journal of critical care medicine: peer-reviewed, official publication of Indian Society of Critical Care Medicine 18(3): 139.

Hansen, Å. M., Hogh, A., Persson, R., Karlson, B., Garde, A. H. and $\varnothing$ rbaek, P. 2006. Bullying at work, health outcomes, and physiological stress response. Journal of psychosomatic research 60(1): 63-72.

Jonas, J. 2016. Making practical use of Maslow's Hierarchy of Needs theory to motivate employees: a case of Masvingo Polytechnic. Journal of Management and Administration 2016(2): 105-117.

Kinman, G. and Jones, F. 2008. A life beyond work? Job demands, work-life balance, and wellbeing in UK academics. Journal of Human Behavior in the Social Environment 17(1-2): 41-60.

Kinnunen, U., Feldt, T., Gerust, S. and Pulkkinen L. 2006. Types of work-family interface: Well-being correlates of negative and positive spillover between work and family life. Scandinavian Journal of Psychology 47: 149-162.

Kozak, A. 2011. Post-modern changes in marital and family life. The Journal of Education, Culture, and Society (1): 73-79.

Lanz, M. and Tagliabue, S. 2007. Do I really need someone in order to become an adult? Romantic relationships during emerging adulthood in Italy. Journal of Adolescent Research 22(5): 531-549.

Lazarus, R., and Folcman, S. 1984. Stress, appraisal, and coping [Stress, appraisal, and coping]. Niu Jork.

Leonard, K. E. and Roberts, L. J. 1998. Marital aggression, quality, and stability in the first year of marriage: Findings from the Buffalo Newlywed Study. The developmental course of marital dysfunction: 44-73.

Li, T. and Fung, H. H. 2011. The dynamic goal theory of marital satisfaction. Review of General Psychology 15(3): 246-254.

López, M. F., Rodríguez, A. N., Fernández, M. S., Marcos, S. A., Martinón, F. T. and Martinón, J. S. 2005. Burnout syndrome among health workers in pediatrics. In Anales de pediatria (Barcelona, Spain: 2003) (Vol. 62, No. 3, pp. 248-251).

Luteijn, F. 1994. Personality and the quality of an intimate relationship. European Journal of Psychological Assessment 10: 220-223.

Marchand, A., Durand, P., Haines, V. and Harvey, S. 2015. The multilevel determinants of workers' mental health: results from the SALVEO study. Social psychiatry and psychiatric epidemiology 50(3): 445-459.

Maslach, C. 2003. Job burnout: New directions in research and intervention. Current directions in psychological science 12(5): 189-192.
Maslach, C. and Jackson, S. E. 1981. The measurement of experienced burnout. Journal of organizational behavior 2(2): 99-113.

Maslach, C. and Jackson, S.E. 1986. Maslach Burnout Inventory; manual research edition. Palo Alto, CA: Consulting Psychologists Press.

Maslach, D., Schaufeli, W. B. and Leiter, M. P. 2001. Job burnout. Annual Review of Psychology 52: 397-422.

Maslow, A. H. 1943. A theory of human motivation. Psychological review 50(4): 370.

Matthiesen, S. B. and Einarsen, S. 2010. Bullying in the workplace: Definition, prevalence, antecedents and consequences. International Journal of Organization Theory and Behavior 13(2): 202-248.

Mathisen, G. E., Einarsen, S. and Mykletun, R. 2011. The relationship between supervisor personality, supervisors' perceived stress, and workplace bullying. Journal of Business Ethics 99(4): 637-651.

McKay, R., Arnold, D. H., Fratzl, J. and Thomas, R. 2008. Workplace bullying in academia: A Canadian study. Employee Responsibilities and Rights Journal 20(2): 77-100.

Mikulincer, M. 2006. Attachment, caregiving, and sex within romantic relationships. Dynamics of romantic love: Attachment, caregiving, and sex: 23-42.

Montgomery, M. 2005. Psychosocial intimacy and identity: From early adolescence to emerging adulthood. Journal of Adolescent Research 20: 346-374

Munley, P. H. 1975. Erik Eriksonss theory of psychosocial development and vocational behavior. Journal of Counseling Psychology 22(4): 314.

Patrick, S., Sells, J. N., Giordano, F. G. and Tollerud, T. R. 2007. Intimacy, differentiation, and personality variables as predictors of marital satisfaction. The family journal 15(4): 359-367.

Pierce, J. L., Gardner, D. G., Cummings, L. L. and Dunham, R. B. 1989. Organization-based self-esteem: Construct definition, measurement, and validation. Academy of Management journal 32(3): 622-648.

Pines, A. and Maslach, C. 1978. Characteristics of staff burnout in mental health settings. Psychiatric services 29(4): 233-237.

Pintrich, P. R. 1991. Editorss comment. Educational Psychologist 26(3-4): 199-205.

Prager, K. J. 1991. Intimacy status and couple conflict resolution. Journal of Social and Personal Relationships 8(4): 505-526.

Redenbach, S. 1991. Self-esteem and Emotional Intelligence: The Necessary Ingredient for Success. Esteem Seminar Programs and Publications.

Reis, H. T. and Franks, P. 1994. The role of intimacy and social support in health outcomes: Two processes or one?. Personal Relationships 1(2): 185-197. 
Repetti, R. and Wang, S. W. 2017. Effects of job stress on family relationships. Current opinion in psychology 13: 15-18.

Røsand, G. M. B., Slinning, K., Røysamb, E. and Tambs, K. 2014. Relationship dissatisfaction and other risk factors for future relationship dissolution: a population-based study of 18,523 couples. Social psychiatry and psychiatric epidemiology 49(1): 109-119.

Rupert, P.A., Stevanovic, P., Tuminello Hartman, E.R., Bryant, F.B. and Miller, A. 2012. Predicting work-family conflict and life satisfaction among professional psychologists. Professional Psychology: Research and Practice 43(4): 341-348.

Rushton, C. H., Batcheller, J., Schroeder, K. and Donohue, P. 2015. Burnout and resilience among nurses practicing in high-intensity settings. American Journal of Critical Care 24(5): 412-420.

Santrock, J. W. 2002. Life span development. New York: McGraw-Hill, Inc.

Sava, F. A. 2002. Causes and effects of teacher conflict-inducing attitudes towards pupils: A path analysis model. Teaching and teacher education 18(8): 1007-1021.

Schaufeli, W. B. and Buunk, B. P. 2003. Burnout: An overview of 25 years of research and theorizing. The handbook of work and health psychology 2(1): 282-424.

Schutte, N., Toppinen, S., Kalimo, R. and Schaufeli, W. 2000. The factorial validity of the Maslach Burnout InventoryGeneral Survey (MBI-GS) across occupational groups and nations. Journal of Occupational and Organizational psychology 73(1): 53-66.
Stephanou, G. 2012. Romantic relationships in emerging adulthood: Perception-partner ideal discrepancies, attributions, and expectations. Psychology 3(2): 150.

Tejada-Vera, B. and Sutton, P. D. 2010. Births, marriages, divorces, and deaths: Provisional data for 2009. National vital statistics reports 58(25): 1-6.

Van Droogenbroeck, F. and Spruyt, B. 2015. Do teachers have worse mental health? Review of the existing comparative research and results from the Belgian Health Interview Survey. Teaching and Teacher Education 51: 88-100.

White, J. K., Hendrick, S. S. and Hendrick, C. 2004. Big five personality variables and relationship constructs. Personality and individual differences 37(7): 1519-1530.

Winefield, A. H., Gillespie, N., Stough, C., Dua, J., Hapuarachchi, J. and Boyd, C. 2003. Occupational stress in Australian university staff: Results from a national survey. International Journal of Stress Management 10(1): 51.

Winstanley, S. and Whittington, R. 2002. Anxiety, burnout and coping styles in general hospital staff exposed to workplace aggression: a cyclical model of burnout and vulnerability to aggression. Work and Stress 16(4): 302-315.

Zineldin, M. and Vasicheva, V. 2016. Marriage versus strategic alliance: soft and hard dissatisfaction and failure factors. International Journal of Strategic Business Alliances 5(1): 22-33. 